\title{
Relationship of mortality to socioeconomic status and some other factors in Sydney in 1971
}

\author{
S. FISHER
}

From the Division of Epidemiology, Health Commission of New South Wales, Sydney

SUMMARY In Sydney in 1971 low socioeconomic status was found to be associated with high mortality and this became more marked with increasing age; it was not statistically significant in relation to infant mortality. Mortality was higher among those born in Australia than among immigrants. A more varied pattern in the differences in cause specific death rates was noted in those born in Australia compared with those born overseas. Socioeconomic status was characterised by an area-type index applied to the results of the 1971 census and calculated for local government areas in the Sydney Statistical Division.

In Western countries the detailed study of mortality by social status appears to have begun during the first quarter of the nineteenth century. The literature has been reviewed by Stockwell (1961, 1963), Benjamin (1965), and Antonovsky (1967). Antonovsky quoted papers by Milne (1815) on class differences and on mortality by Villerme (1840), who analysed life expectancy of persons in different occupations from deaths in Mulhouse between 1823 and 1834. Studies by Corbeaux (1833) were referred to by Stockwell (1961). Studies by Farr (1843) on population density and mortality, and by Radcliffe (1850) on occupational correlations were referred to by Benjamin (1965). In subsequent work, urbanisation, housing, nutrition, occupation, educational level, income, and marital state were among the environmental factors studied in relation to mortality.

Occupation and educational level have been used as indices of socioeconomic status. In many studies, data from death registration have been related to those from censuses although data from the two sources are not necessarily comparable (Stockwell, 1961). A much more precise technique was used by Kitagawa and Hauser (1973) who matched death certificates with census records on a sample of 340000 deaths in the United States in 1960.

In Australia, there is little information on the relationship between mortality and socioeconomic status (National Population Inquiry, 1975). The development of a socioeconomic index by the Australian Bureau of Statistics has provided data not previously available for studies of this type.

\section{Data and methods}

The 1971 census carried out on 30 June showed the total population of the Sydney Statistical Division as 2807828 persons (1 023581 Australianborn males, 1085807 Australian-born females; 369892 males and 328548 females born overseas). In the same year 25461 deaths were registered (9391 in Australian-born males, 9475 in Australianborn females; 3561 in males born abroad and 2629 in females born abroad, while the place of birth was not stated for 272 males and 133 females).

The socioeconomic index used is an area index calculated by the Australian Bureau of Statistics for collectors' districts from data in the 1971 census. The index is the sum of 18 weighted ratios each assigned $\mathrm{a}+$ or - sign according to whether it is an indicator of higher or lower status. The variables in the ratios refer to occupation, education, religion, marital state, and ownership of the dwelling by the occupier. Thus, for example, one weighted ratio is $+0.836 \mathrm{X}_{13}$ where ' $\mathrm{X}_{13}=$ full-time students/ persons aged 15 to $24^{\prime}$, and another is $-2.448 X_{14}$ where ' $\mathrm{X}_{14}=$ not proceeded beyond level 6 schooling/persons aged 15 or more' (information supplied by the Australian Bureau of Statistics). The 18 weighted ratios were summed for each collector's district. The index is slightly different for urban and rural areas.

For administrative purposes, the Sydney Statistical Division is divided into 41 local government areas (LGAs). The Australian Bureau of Statistics calculated an index value for each LGA by 
averaging the values of the constituent collectors' districts. The number of deaths in persons domiciled in the LGAs in the same year (1971) grouped according to gender, age group, whether born in Australia, and cause of death was available. The number of live births in the LGAs by sex and the population data from the 1971 census were also provided.

Death rates were standardised for age by the 'direct' method (Barclay, 1958). The standard populations used were the male and female census populations in the Sydney Statistical Division in 1971. The method of least squares was used to compute the constants in the equations of the lines of best fit. Spearman's rank order correlation coefficient was calculated where applicable and its significance determined from the tables given by Owen (1962).

\section{Results}

The 41 LGAs were arranged in ascending order according to the socioeconomic index and divided into 10 groups ( 9 of 4 LGAs and 1 of 5). For each group the average index value (that is, the weighted average of the means of the values for individual LGAs) was calculated (Table 1). Age standardised death rates were calculated for each LGA group separately for the two sexes, for the age groups $0-39,0-59$, and for all ages. The rates were determined firstly irrespective of place of birth and secondly for those born in Australia, and were plotted against the index values for each LGA. Inspection suggested linear relationships. The lines of best fit were calculated and plotted (Figs 1-4).

Negative correlation was noted between socioeconomic index and mortality for both sexes and all age groups, irrespective of the country of birth. The slope of the lines was greater when higher age
Table 1 Socioeconomic index for local government areas (LGAs) in 10 ordered groups

\begin{tabular}{|c|c|c|}
\hline$L G A$ & $\begin{array}{l}\text { No. of } \\
\text { collectors' } \\
\text { districts }\end{array}$ & $\begin{array}{l}\text { Socioeconomic } \\
\text { index }\end{array}$ \\
\hline $\begin{array}{l}\text { South Sydney } \\
\text { Marrickville } \\
\text { Botany } \\
\text { Fairfield }\end{array}$ & 379 & $-3 \cdot 44$ \\
\hline $\begin{array}{l}\text { Leichhardt } \\
\text { Auburn } \\
\text { Liverpool } \\
\text { Holroyd }\end{array}$ & 345 & $-2 \cdot 13$ \\
\hline $\begin{array}{l}\text { Blacktown } \\
\text { Canterbury } \\
\text { Bankstown } \\
\text { Burwood }\end{array}$ & 574 & $-1 \cdot 57$ \\
\hline $\begin{array}{l}\text { Ashfield } \\
\text { Concord } \\
\text { Parramatta } \\
\text { Drummoyne }\end{array}$ & 282 & $-1 \cdot 20$ \\
\hline $\begin{array}{l}\text { Penrith } \\
\text { Rockdale } \\
\text { Sydney } \\
\text { Randwick }\end{array}$ & 516 & -0.67 \\
\hline $\begin{array}{l}\text { Cambelltown } \\
\text { Strathfield } \\
\text { Hurstville } \\
\text { Waverley }\end{array}$ & 291 & $0 \cdot 28$ \\
\hline $\begin{array}{l}\text { Ryde } \\
\text { Kogarah } \\
\text { Camden } \\
\text { Windsor }\end{array}$ & 224 & 0.81 \\
\hline $\begin{array}{l}\text { Sutherland } \\
\text { Warringah } \\
\text { Manley } \\
\text { Willoughby } \\
\text { Hunters Hill }\end{array}$ & 599 & 1.48 \\
\hline $\begin{array}{l}\text { Blue Mountains } \\
\text { Baulkham Hills } \\
\text { Woollahra } \\
\text { North Sydney }\end{array}$ & 335 & $1 \cdot 76$ \\
\hline $\begin{array}{l}\text { Hornsby } \\
\text { Lane Cove } \\
\text { Mosman } \\
\text { Ku-ring-gai }\end{array}$ & 356 & 3.67 \\
\hline $\begin{array}{l}\text { Sydney Statistical } \\
\text { Division }\end{array}$ & 3901 & -0.11 \\
\hline
\end{tabular}

groups were included. This indicates that the mortality differential according to socioeconomic status increases with age since, in the 0-59 group most deaths occurred between the ages of 50 and 59 , and in the all ages group most deaths were over the age of 65 (Table 2).

Table 2 Deaths and death rates by age, sex and place of birth, Sydney Statistical Division

\begin{tabular}{|c|c|c|c|c|c|c|c|c|}
\hline \multirow{3}{*}{$\begin{array}{l}\text { Age } \\
\text { (years) }\end{array}$} & \multicolumn{4}{|l|}{ Deaths* } & \multicolumn{4}{|c|}{ Death rate per 1000 population } \\
\hline & \multicolumn{2}{|c|}{ Males born } & \multicolumn{2}{|c|}{ Females born } & \multicolumn{2}{|c|}{ Males born } & \multicolumn{2}{|c|}{ Females born } \\
\hline & Australia & Overseas & Australia & Overseas & Australia & Overseas & Australia & Overseas \\
\hline Allt & & & & & $9 \cdot 82$ & $8 \cdot 44$ & $8 \cdot 96$ & $7 \cdot 49$ \\
\hline
\end{tabular}

* Fractional values due to proportionate distribution of cases when place of birth not stated † Age standardised death rate 

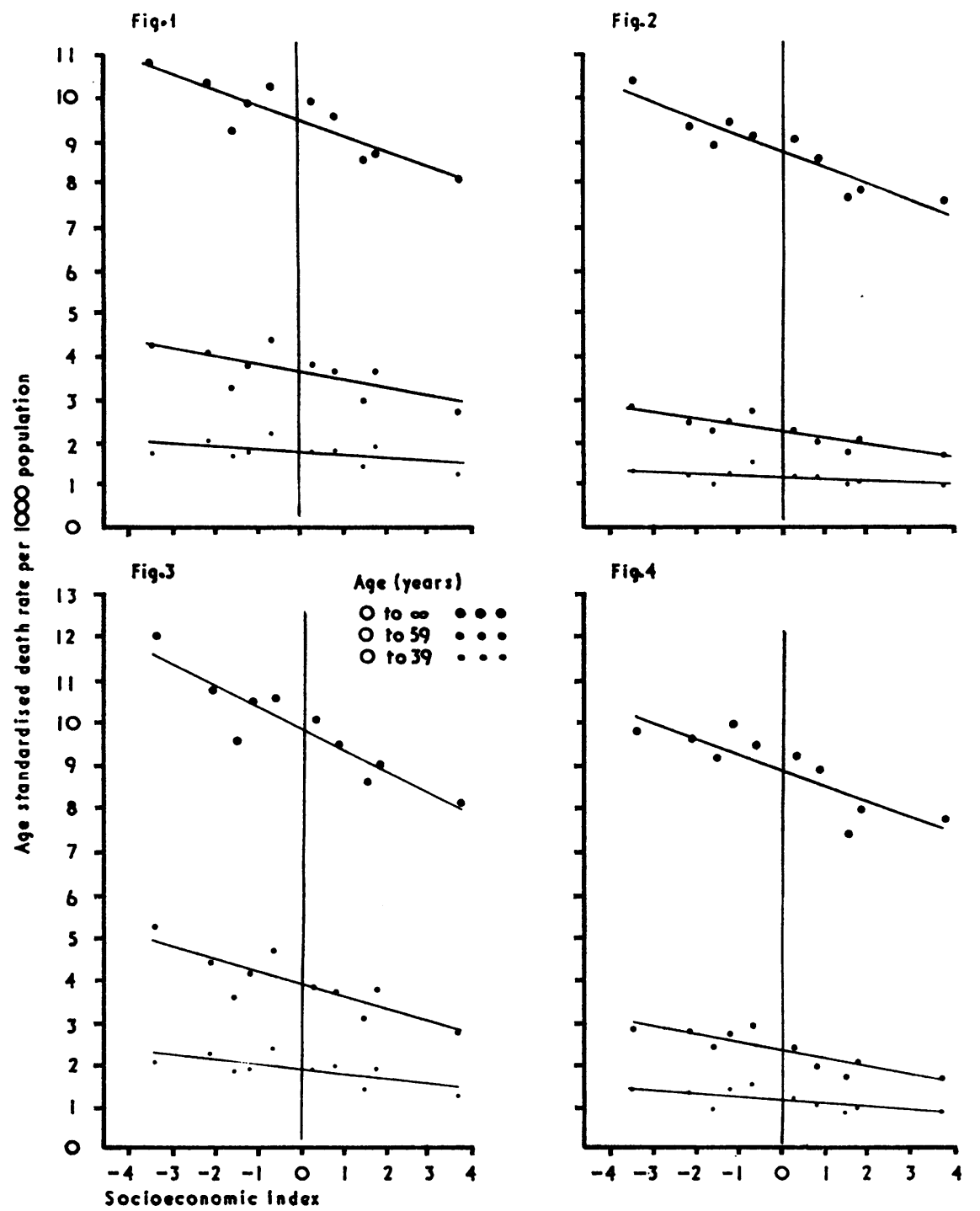

Relationship between socioeconomic status and age-standardised death rates in grouped LGAs. Fig. 1 All males; Fig. 2 All females; Fig. 3 Australian-born males; Fig. 4 Australian-born females.

The constants of the lines of best fit and the coefficients of correlation as well as their significance are set out in Table 3. The results obtained in relation to infant mortality will be discussed below. In all other groups, in comparisons between those of corresponding age, the slopes of the lines were greater for males than for females, for Australianborn males than for all males, and for Australianborn females than for all females. Further the correlation coefficients and their significance in- creased with age irrespective of sex and place of birth; the correlations were significant for all groups except males under the age of $\mathbf{4 0}$.

It appeared that those born abroad showed lower mortality than native-born Australians. To examine this matter in greater detail, age specific and age standardised death rates were calculated (Table 2). The age standardised death rate was highest in Australian-born males, lower in Australian-born females, lower still in males born overseas, and 
Table 3 Relationship between death rate and socioeconomic index in grouped LGAs

\begin{tabular}{|c|c|c|c|c|c|c|}
\hline \multirow{2}{*}{ Place of birth } & \multirow{2}{*}{$\operatorname{Sex}$} & \multirow{2}{*}{ Age (years) } & \multicolumn{2}{|c|}{$\begin{array}{l}\text { Constants of equation of line } \\
\text { of best fit }(y=a+b x)^{*}\end{array}$} & \multicolumn{2}{|c|}{$\begin{array}{l}\text { Spearman's rank order } \\
\text { correlation coefficient } \\
\text { and its significance }\end{array}$} \\
\hline & & & $\bar{a}$ & $b$ & rho & $P$ \\
\hline All places & $\begin{array}{l}\text { M } \\
\text { F }\end{array}$ & $\begin{array}{l}0-39 \\
0-59 \\
\text { All } \\
0-39 \\
0-59 \\
\text { All }\end{array}$ & $\begin{array}{l}1 \cdot 732 \\
3 \cdot 543 \\
9 \cdot 330 \\
1 \cdot 158 \\
2 \cdot 161 \\
8 \cdot 516\end{array}$ & $\begin{array}{l}-0.071 \\
-0.186 \\
-0.364 \\
-0.045 \\
-0.154 \\
-0.396\end{array}$ & $\begin{array}{l}-0.224 \\
-0.673 \\
-0.830 \\
-0.612 \\
-0.818 \\
-0.891\end{array}$ & $\begin{array}{l}0.3 \\
0.02 \\
0.002 \\
0.03 \\
0.003 \\
0.0006\end{array}$ \\
\hline Australia & $\begin{array}{l}\mathbf{M} \\
\mathbf{F}\end{array}$ & $\begin{array}{l}0-39 \\
0-59 \\
\text { All } \\
0-39 \\
0-59 \\
\text { All }\end{array}$ & $\begin{array}{l}1 \cdot 825 \\
3 \cdot 744 \\
9 \cdot 617 \\
1 \cdot 219 \\
2 \cdot 306 \\
8 \cdot 745\end{array}$ & $\begin{array}{l}-0.109 \\
-0.285 \\
-0.495 \\
-0.070 \\
-0.179 \\
-0.365\end{array}$ & $\begin{array}{l}-0.539 \\
-0.721 \\
-0.903 \\
-0.612 \\
-0.770 \\
-0.830\end{array}$ & $\begin{array}{l}0.06 \\
0.01 \\
0.004 \\
0.03 \\
0.006 \\
0.002\end{array}$ \\
\hline $\begin{array}{l}\text { Infant mortality rate } \\
\text { All places }\end{array}$ & $\stackrel{\mathbf{M}}{\mathbf{F}}$ & & $\begin{array}{l}19 \cdot 415 \\
15 \cdot 800\end{array}$ & $\begin{array}{l}-0.763 \\
-0.141\end{array}$ & $\begin{array}{r}-0.455 \\
0.006\end{array}$ & $\begin{array}{l}0.1 \\
0.5\end{array}$ \\
\hline
\end{tabular}

lowest in females born outside Australia. At ages 0-4 and at all ages over 30 the age and sex specific death rates were higher in Australian-born than in those born overseas. Between the ages of 5 and 29 these differences were not observed consistently; however, the number of deaths was very small, particularly among those born abroad.

The observed variations in mortality according to socioeconomic status might have been affected by the proportions of immigrants in the different locations. These proportions were therefore determined. Among the males, $29.4 \%$ had been born abroad in LGAs with socioeconomic indices 1 to 5 , and $22.7 \%$ where the socioeconomic index was 6 to 10. The corresponding proportions among females were $25 \cdot 6 \%$ and $20 \cdot 2 \%$ respectively. Thus, relatively more immigrants (with lower mortality) lived in the areas with higher overall mortality, and vice versa. If the proportions of those born! overseas had been uniform throughout the areas studied, the differences in death rates according to

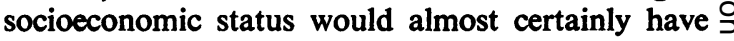
been greater.

The differences between age standardised deat rates from selected causes or groups of causes wer examined. For the comparison according to socies economic status, the population was divided into $\overrightarrow{0}$ two groups: socioeconomic index 1 to 5 , and 6 to 10 . A more detailed analysis using five groups (socioeconomic index 1 and 2, 3 and 4, etc.) did not yield significantly more information. The findings are shown in Table 4.

Table 4 Age standardised cause specific death rates per 1000 population for selected diseases or groups of diseases (all ages)

\begin{tabular}{|c|c|c|c|c|c|c|c|c|}
\hline \multirow{4}{*}{ Certified cause of death and ICD $†$ code } & \multicolumn{8}{|c|}{ Country of birth } \\
\hline & \multicolumn{4}{|l|}{ All places } & \multicolumn{2}{|l|}{ Australia } & \multicolumn{2}{|l|}{ Overseas } \\
\hline & \multicolumn{2}{|l|}{$1-5^{*}$} & \multicolumn{2}{|l|}{$6-10^{*}$} & \multicolumn{4}{|l|}{$1-10^{*}$} \\
\hline & $\begin{array}{l}\text { Males } \\
\text { (801 427) }\end{array}$ & $\begin{array}{l}\text { Females } \\
(791444)\end{array}$ & $\begin{array}{l}\text { Males } \\
(592046)\end{array}$ & $\begin{array}{l}\text { Females } \\
(622911)\end{array}$ & $\begin{array}{l}\text { Males } \\
110235\end{array}$ & $\begin{array}{l}\text { Females } \\
\text { 581) }(1085807)\end{array}$ & $\begin{array}{l}\text { Males } \\
\text { (369 892) }\end{array}$ & $\begin{array}{l}\text { Females } \\
\text { (328 548) }\end{array}$ \\
\hline \multirow{5}{*}{$\begin{array}{l}\text { Malignant neoplasm of trachea, } \\
\text { bronchus, and lung (162) } \\
\text { Malignant neoplasm of breast (174) } \\
\text { Other neoplasms (rest of 140-239) } \\
\text { Diabetes mellitus (250) } \\
\text { Alcoholism (303), drug dependence (304) } \\
\text { Ischaemic heart disease (410-414) } \\
\text { Cerebrovascular disease (430-438) } \\
\text { Other diseases of the circulatory system } \\
\text { (rest of 390-458) } \\
\text { Bronchitis, emphysema, asthma } \\
\text { (490-493) } \\
\text { Other diseases of the respiratory system } \\
\text { (rest of 460-519) } \\
\text { Motor vehicle accidents (810-819 } \\
\text { Suicide and self-inflicted injury } \\
\text { (950-959) } \\
\text { All others (rest of 0-999) } \\
\text { All (0-999) }\end{array}$} & $\begin{array}{l}0.52 \\
0.00 \\
1.23 \\
0.12 \\
0.06 \\
3.17 \\
1.14\end{array}$ & $\begin{array}{l}0.08 \\
0.24 \\
1.03 \\
0.20 \\
0.05 \\
2.67 \\
1.85\end{array}$ & $\begin{array}{l}0.41 \\
0.00 \\
1.22 \\
0.12 \\
0.03 \\
3.12 \\
1.06\end{array}$ & $\begin{array}{l}0.09 \\
0.27 \\
1.06 \\
0.14 \\
0.04 \\
2.19 \\
1.68\end{array}$ & $\begin{array}{l}0.48 \\
0.00 \\
1.24 \\
0.11 \\
0.05 \\
3.27 \\
1.16\end{array}$ & $\begin{array}{l}0.07 \\
0.24 \\
1.07 \\
0.17 \\
0.05 \\
2.55 \\
1.83\end{array}$ & $\begin{array}{l}0.44 \\
0.00 \\
1.19 \\
0.13 \\
0.03 \\
2.88 \\
0.97\end{array}$ & $\begin{array}{l}0.12 \\
0.29 \\
0.97 \\
0.17 \\
0.02 \\
2.09 \\
1.59\end{array}$ \\
\hline & $0 \cdot 77$ & $1 \cdot 12$ & 0.73 & 0.90 & 0.78 & 1.04 & 0.69 & 0.94 \\
\hline & 0.60 & $0 \cdot 16$ & 0.38 & 0.13 & 0.54 & $0 \cdot 16$ & 0.41 & $0 \cdot 10$ \\
\hline & $\begin{array}{l}0 \cdot 36 \\
0 \cdot 37\end{array}$ & $\begin{array}{l}0 \cdot 30 \\
0 \cdot 13\end{array}$ & $\begin{array}{l}0 \cdot 25 \\
0 \cdot 30\end{array}$ & $\begin{array}{l}0 \cdot 26 \\
0 \cdot 11\end{array}$ & $\begin{array}{l}0 \cdot 31 \\
0 \cdot 34\end{array}$ & $\begin{array}{l}0 \cdot 29 \\
0 \cdot 12\end{array}$ & $\begin{array}{l}0 \cdot 26 \\
0 \cdot 32\end{array}$ & $\begin{array}{l}0 \cdot 26 \\
0 \cdot 13\end{array}$ \\
\hline & $\begin{array}{l}0.21 \\
1.44 \\
9.98\end{array}$ & $\begin{array}{l}0 \cdot 14 \\
1 \cdot 29 \\
9 \cdot 26\end{array}$ & $\begin{array}{l}0 \cdot 15 \\
1 \cdot 11 \\
8 \cdot 87\end{array}$ & $\begin{array}{l}0.10 \\
1.00 \\
7.97\end{array}$ & $\begin{array}{l}0.18 \\
1.35 \\
9.82\end{array}$ & $\begin{array}{l}0 \cdot 12 \\
1 \cdot 24 \\
8 \cdot 96\end{array}$ & $\begin{array}{l}0.20 \\
0.91 \\
8.45\end{array}$ & $\begin{array}{l}0.11 \\
0.69 \\
7.49\end{array}$ \\
\hline \multicolumn{9}{|l|}{$\begin{array}{l}\text { Socioeconomic index } \\
\text { tWorld Health Organisation (1967) }\end{array}$} \\
\hline
\end{tabular}


Male mortality was higher than female from neoplastic disease (other than cancer of the breast), ischaemic heart disease, obstructive air-way disease and asthma, motor accidents, and grouped causes not specifically named in the table. Female mortality was higher for diabetes and cardiovascular causes other than ischaemic heart disease, particularly cerebrovascular disease. The differences were slight or inconsistent for deaths attributed to alcoholism, drug dependence, and respiratory diseases other than those mentioned.

Among men, lower socioeconomic status was linked with higher mortality from all causes except diabetes and, among women, from all causes other than neoplastic diseases. Some sex differentials may be noted. For example, mortality from all circulatory diseases in males was 5.08 in areas with socioeconomic index 1 to 5 and 4.91 in areas with index 6 to 10. For females the corresponding figures were $5 \cdot 64$ and $4 \cdot 77$, giving ratios of lower/ upper status groups of $1 \cdot 03: 1$ and $1 \cdot 18: 1$, respectively. For deaths from all types of respiratory disease, the corresponding rates were 0.96 and 0.63 for males and 0.46 and 0.39 for females, with ratios of $1.52: 1$ for males and 1.17:1 for females. Thus, in the lower socioeconomic groups, females appeared disadvantaged in respect of cardiovascular diseases and males in respect of respiratory causes.

In the comparison according to place of birth, mortality among Australian males was higher from all causes except diabetes and suicide. Mortality from lung and breast cancers among Australian women was lower than among women born overseas. The rates were similar for diabetes, motor accidents and suicide, and were higher among Australian-born women for all other causes.

In the Sydney Statistical Division in 1971, there were 31009 male and 29386 female live births, and 604 deaths in males and 465 deaths in females under the age of one year, giving infant mortality rates of 19.48 in males and 15.82 in females. Very pronounced scatter of the points was noted when the rates in the LGA groups were plotted against the socioeconomic index values. Although a negative correlation was present for males, it did not reach the level conventionally regarded as significant (Table 4).

\section{Discussion}

In his survey of the literature, Antonovsky (1967) found no report on life expectancy in different social classes for periods earlier than the nineteenth century. He considered that class differences widened about that time or perhaps before it. Most investigations reviewed by him have shown a negative correlation between social class and mortality. In more than 30 studies cited, there were only three in which this correlation was slight or absent. In two of these, Antonovsky judged the classifications as too gross to reveal fine differences. However, he accepted the validity of the study of de Wolff and Meerdink (1954) carried out in Amsterdam in 1947-52. He pointed out that the death rate in the Netherlands was very low at the time covered by the study, and proposed the hypothesis that the lowering of the overall death rate and the lessening of class differences may be linked.

The results presented here show that the negative correlation between socioeconomic status and mortality became stronger with increasing age. This contrasts with a consistent trend in the papers reviewed by Antonovsky (1967) where class differentials were greatest in the middle age group and declined at the older ages. The differences in the findings may be owing to the indices used to rank socioeconomic status. The analysis of Kitagawa and Hauser (1973) has demonstrated the complexity of these factors.

The main reasons for the age differential may be those suggested by Antonovsky: that the lower social classes benefited more from the successful prevention and treatment of infectious disease than they did from advances in combating chronic illness. This is supported by the persistence in the United States of class differentials in mortality from degenerative diseases (Kitagawa and Hauser, 1973). For each cause of death, mortality was consistent (higher among the lower socioeconomic groups) but the magnitude of the difference varied for different diseases and this variation was greater among men. A possible explanation of mortality differentials which increased progressively with age in a cross-sectional analysis might be differences between cohorts. In view of the findings, future longitudinal studies in Australia may be of interest, although in the United States where conditions are similar, no change was noted over a few decades (Kitagawa and Hauser, 1973).

It may seem surprising that the death rate of native-born Australians was higher than that of immigrants. However, the two populations do not necessarily have similar life expectations. Good health has been a condition of admission to the country for most immigrants, who therefore represent a selected group. The fitness on arrival of those born abroad appears to have outweighed the adverse effects of the hardships they had to face in a new country. Contrary to the overall trend, some of the cause specific death rates were found 
to be higher in immigrants than in those born in Australia. This presumably reflects differences in risks experienced before, or possibly after, arrival. Since the immigrants came from widely varying environments and cultural backgrounds, the factors bearing on the differences in the distribution of the causes of death would be difficult to identify.

I should like to thank the Australian Bureau of Statistics for the provision of the data which made this study possible, Dr N. I. Fisher for help with the statistical aspects, and Ms Chris Schafer for computer work required to produce Table 4.

Reprints from S. Fisher, Multiple Sclerosis Society of New South Wales, P.O. Box 364, Artarmon, New South Wales, Australia.

\section{References}

Antonovsky, A. (1967). Social class, life expectancy and overall mortality. Milbank Memorial Fund Quarterly, 45, 31-73.

Barclay, G. W. (1958). Techniques of Population Analysis. Wiley: New York.
Benjamin, B. (1965). Social and Economic Factors $\bigcirc$ Affecting Mortality. Confluence, volume 5. Mouton: The Hague.

de Wolff, P., and Meerdink, J. (1954). Les taux de la mortalité selon la profession a Amsterdam. Proceedings of the World Population Conference, volume $1, \frac{T}{\mathbb{D}}$ E/Conf./13/413. United Nations: New York.

Kitagawa, E. M., and Hauser, P. M. (1973). Differential Mortality in the United States: A Study in Socio- $\vec{F}$ economic Epidemiology. Harvard University Press: ? Cambridge, Mass.

National Population Inquiry (1975). Population and $\frac{\bar{D}}{2}$ Australia. A Demographic Analysis and Projection. First Report of the National Population Inquiry, $\mathbb{\otimes}$ volume 1. Government Printer of Australia: Canberra.

Owen, D. B. (1962). Handbook of Statistical Tables. Addison-Wesley: Reading, Mass.

Stockwell, E. G. (1961). Socioeconomic status and mortality in the United States. Public Health Reports, 76, 1081-1086.

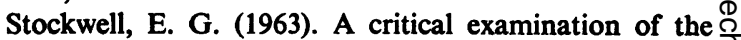
relationship between socioeconomic status and mort- $\dot{\omega}$ ality. American Journal of Public Health and the $?^{N}$ Nation's Health, 53, 956-964.

World Health Organisation (1967). International Classifi- $\vec{A}$ cation of Diseases, 8th revision. WHO: Geneva. 